\title{
Técnicas de Fortalecimento da Musculatura Respiratória Auxiliando o Desmame do Paciente em Ventilação Mecânica Invasiva
}

\section{Tecnics for the Strengthening os Respiratory Muscles to Help the Weaning from Patients under Mechanical Ventilation}

\section{Artigo}

Original

\section{Original}

Paper

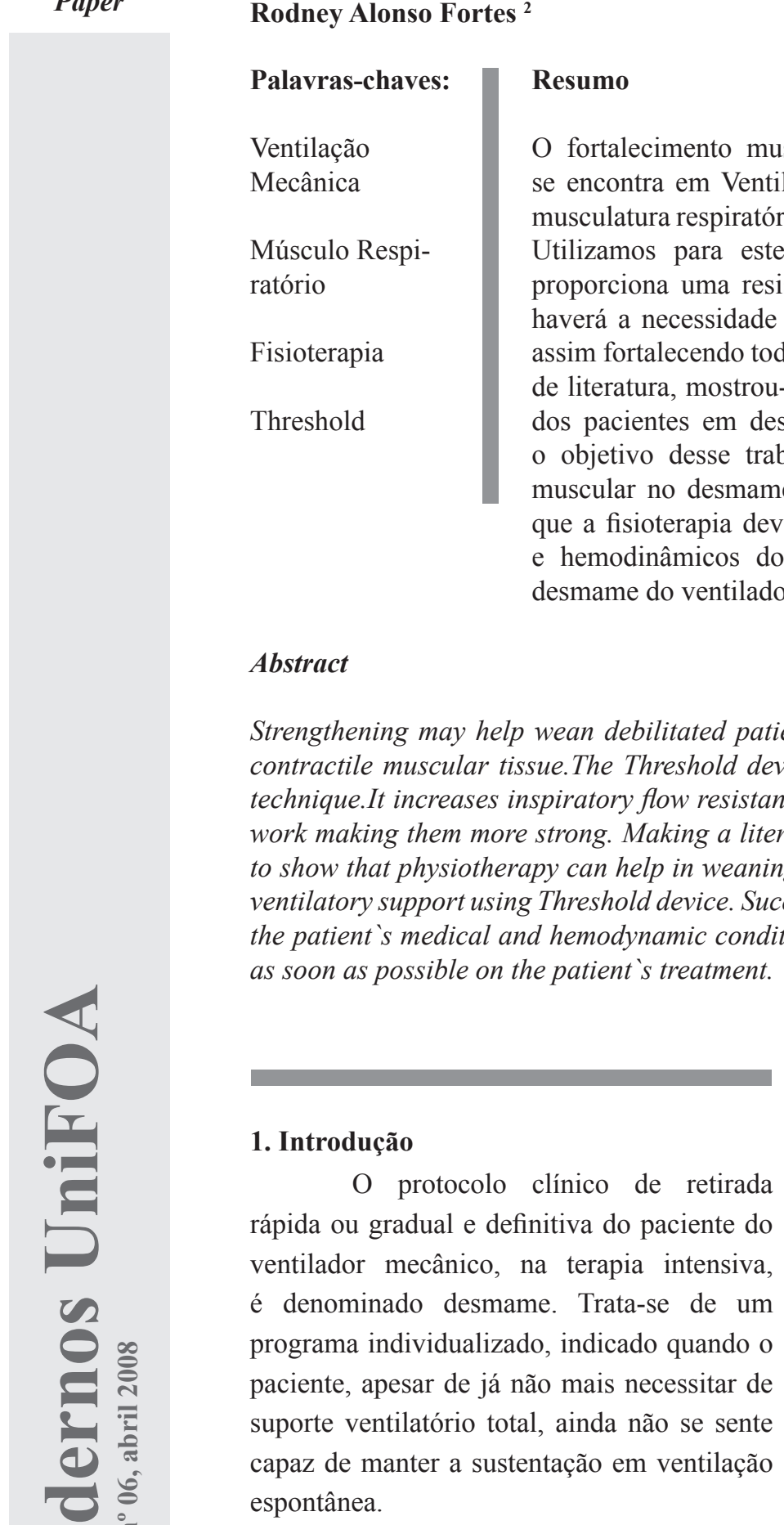

Assim, o desmame deve ser iniciado

\author{
Cleize Silveira Cunha ${ }^{1}$ \\ Elber Rodrigues Manso Santana ${ }^{2}$ \\ Rodney Alonso Fortes ${ }^{2}$
}

Palavras-chaves:

Ventilação

Músculo Respi-

Fisioterapia de literatura, mostrou-se como a fisioterapia pode auxiliar na reabilitação pacientes em desmame da ventilação mecânica invasiva. Portanto, e hemodinâmicos do paciente estejam estabilizados, dando início ao desmame do ventilador mecânico, utilizando o aparelho threshold.
Key words:

Mechanical

Ventilation

Respiratory

Muscles

Physiotherapy

Threshold

Mestranda - Fisioterapia - UniFOA

${ }^{2}$ Fisioterapeutas

quando o quadro agudo do paciente estiver estabilizado e quando tiver completa reversão da insuficiência respiratória.

Recomenda-se que o desmame seja efetivado, se possível, na posição fowler, preferencialmente durante o dia, pois além de permitir que, em pacientes conscientes, o rendimento do trabalho seja máximo, devido à reinstituição do ritmo do sono, ainda facilite providências mais rápidas e seguras em casos 
de eventuais complicações.

Todas essas particularidades, aliadas ainda à duração do suporte ventilatório e ao nível de agressividade das condutas médicas, não afastam definitivamente um insucesso de tal protocolo, já que a ventilação por tempo prolongado pode, apesar das precauções e cuidados, resultar em doença pulmonar crônica, exacerbada por infecção aguda ou qualquer outro tipo de processo agudo.

Assim sendo, este estudo foi direcionado para o fortalecimento da musculatura respiratória, visando ao desmame do paciente em ventilação mecânica invasiva, ou seja, aquele no qual a retirada do suporte ventilatório não é tão simples, podendo ocasionar insucesso desta conduta.

Vários fatores podem ser a causa do insucesso, tais como a hipoxemia arterial ocasionando uma disfunção pulmonar; a hipercapnia e, a principal delas, que é a fadiga dos músculos respiratórios pelo desuso, caracterizada por diminuição da capacidade pulmonar total, capacidade vital, tosse e ventilação alveolar.

Sendo assim, é necessária a adoção de medidas preventivas para se evitar ou diminuir complicações. Será de suma importância, realização de exercícios específicos e constantes para um real e efetivo condicionamento dos músculos respiratórios. Portanto, o treinamento muscular respiratório deve ser realizado desde o momento em que o paciente, sob ventilação mecânica, estiver com prognóstico para iniciar o desmame.

O treinamento muscular respiratório objetiva o restabelecimento da função dos músculos respiratórios, melhorando sua força e endurance.

Em pacientes submetidos à ventilação mecânica invasiva por tempo prolongado, este treinamento visa minimizar a atrofia e fraqueza dos músculos respiratórios, evitando a fadiga que, por sua vez retarda o processo de desmame. Nesse caso, o treinamento pode ser realizado com threshold, com o ajuste da sensibilidade do próprio respirador ou com o uso da estimulação elétrica diafragmática, com o objetivo de melhorar a função dos músculos respiratórios, em especial do diafragma.

Este trabalho de pesquisa, baseado em revisão de literatura, visa fazer uma análise dos recursos fisioterapêuticos no fortalecimento da musculatura respiratória visando o desmame do paciente em ventilação mecânica.

\section{Fisiologia Respiratória}

A fisiologia respiratória tem como enfoque primário o ciclo ventilatório e as trocas gasosas que são de fundamental importância para a manutenção da vida. A respiração tem como principal meta o fornecimento de oxigênio para os tecidos a fim de nutri-los (JARDIM, 1998).

\subsection{Inspiração}

Segundo West (1990) durante a inspiração a partir da CRF, a contração diafragmática empurra o pulmão para baixo, sobre as vísceras abdominais e desloca a parede torácica para fora. O diafragma também eleva as costelas inferiores lateralmente, enquanto os intercostais externos elevam as costelas para cima e para fora e estabilizam a caixa torácica. A expansão do tórax opõese à retração elástica dos pulmões, cria uma pressão pleural mais negativa e aumenta a diferença de pressão entre o espaço pleural e os alvéolos; essa diferença é chamada pressão transpulmonar. A expansão torácica poderia tracionar as superfícies pleurais, separandoas, se o espaço pleural não contivesse líquido incompreensível e inexpansível; em vez disso, a expansão aumenta o volume dos pulmões. O aumento de volume pulmonar, por sua vez, cria uma pressão subatmosférica nos alvéolos, para os quais há fluxo de ar porque a pressão dos pulmões é mais baixa que na boca.

A inflação até a capacidade pulmonar total (CPT) requer atividade contínua dos músculos respiratórios.

\subsection{Expiração}

Depois que a contração muscular se conclui, ao final da inspiração, cessa o fluxo aéreo porque já não existe um gradiente de pressão entre os alvéolos e a boca. A retração elástica dos pulmões faz então com que a pressão alveolar exceda a pressão atmosférica e o ar flui para fora dos pulmões até que o gradiente de pressão já não exista, na CRF. Embora os músculos respiratórios sejam passivos durante a expiração normal, a contração dos músculos abdominais forçará os 
pulmões até seu volume residual (VR).

\subsection{Força muscular respiratória}

A medição da força muscular respiratória é feita através das medições das pressões máximas inspiratórias e expiratórias, com um manômetro. Aceita-se como pressão inspiratória máxima normal, para um jovem adulto masculino por volta de $-125 \mathrm{cmH} 2 \mathrm{O}$ e de pressão expiratória máxima de +230 $\mathrm{cmH} 2 \mathrm{O}$, e em mulheres esse valor diminui em $30 \%$, após os 20 anos de idade há uma queda de $0,5 \mathrm{cmH} 2 \mathrm{O}$ por ano (PRESTO 2003).

\subsection{Endurance muscular}

Segundo Knobel (2004), endurance muscular é a capacidade do músculo em oferecer resistência à fadiga, em um determinado tempo de trabalho. A capacidade de endurance muscular depende do tipo de fibras, do suprimento sangüíneo e da integridade dos elementos contráteis.

Os testes de endurance muscular são:

- Método de hiperpnéia .

-Ventilação voluntária máxima (VMM)

- Capacidade ventilatória máxima (CVSM) Índice tensão-tempo - Pdi/Pdimax.

\section{Músculos}

\subsection{Musculatura Respiratória}

Os músculos respiratórios são constituídos por fibras estriadas e apresentam $55 \%$ de fibras estriadas do tipo I vermelhas (resistentes a fadiga) e $45 \%$ de fibras estriadas tipo II brancas (fatigáveis). Os músculos respiratórios trabalham, vencendo cargas elásticas que são as forças de retração dos pulmões e caixa torácica e cargas resistivas das vias aéreas.

Os músculos respiratórios contraemse de maneira rítmica, intermitente e durante toda a vida.

\subsubsection{Músculos Inspiratórios}

a) Diafragma - principal músculo inspiratório, com forma de cúpula voltada cranialmente, e separa a cavidade abdominal da cavidade torácica.

É constituído de uma camada muscular que se origina nas costelas inferiores e coluna lombar que se inserem no tendão central. É inervado pelo nervo frênico, que sai das raízes de $\mathrm{C} 3$ a $\mathrm{C} 5$. $\mathrm{Na}$ inspiração de repouso o diafragma é responsável por $70 \%$ do volume inspirado (MOORE E DALLEY, 2001).

De acordo com David (2001), quando o diafragma se contraí, o conteúdo abdominal é deslocado para baixo e para frente, aumentando o diâmetro céfalo-caudal do tórax, a parte distal das costelas são levantadas e giram para fora.

Em repouso, o deslocamento do diafragma é aproximadamente de $1 \mathrm{~cm}$, e, na inspiração forçada, pode chegar até a $10 \mathrm{~cm}$.

As fibras musculares do diafragma são divididas em porção costal e porção vertebral; as fibras posteriores, vertebrais, originam-se nas 3 primeiras vértebras lombares e nos ligamentos arqueados medial e lateral. As fibras costais originam-se, anteriormente, no processo xifóide do esterno e nas margens superiores das seis últimas costelas.

Em estudos isolados dessas porções, observou-se que as fibras costais, ao se contraírem, fazem a cúpula diafragmática descer, aumentando a pressão abdominal, e assim, a caixa torácica move-se através do movimento de alça de balde. Quando a porção vertebral se contrai, a cúpula diafragmática desce e aumenta a pressão abdominal, porém não age sobre o gradil costal.

As fibras costais do diafragma justapõem-se ao gradil costal, a essa área dáse o nome de área de aposição.

A configuração geométrica do diafragma é a convexidade voltada para cima, a forma de cúpula do diafragma produz um raio de curvatura na convexidade, que obedece à lei de Laplace ( $\mathrm{P}=$ Tensão/raio de curvatura), quando o diafragma esta alongado, o raio de curvatura está menor, portanto, desenvolve mais tensão do que se estivesse aplainado, e com o raio de curvatura aumentado.

b) Músculos Intercostais - localizamse entre as costelas; o músculo intercostal interno vai desde o esterno até o ângulo da costela e subdivide-se em porção intercondral (paraesternal) e interóssea. O músculo intercostal externo vai desde a articulação costovertebral até a origem da cartilagem 
costal. São inervados pelos nervos intercostais que são derivados do 10 ao 12 o segmento torácico.

Há muitas controvérsias sobre as ações da musculatura intercostal, na respiração, mas basicamente o músculo intercostal externo e a porção intercondral do intercostal interno são inspiratórios e a porção interóssea do intercostal interno é expiratória.

c) Escalenos - os músculos escalenos se originam das 5 últimas vértebras cervicais e inserem na borda superior da primeira costela, porção medial e anterior. Quando se contraem, elevam as costelas e o esterno, no movimento denominado braço de bomba.

Em estudos feitos por De Troyer, observou-se que em pessoas normais, na posição sentada, sempre há contração dos paraesternais e dos escalenos durante a inspiração de repouso, não havendo razão para classificar os escalenos como músculos acessórios, mas sim como músculo principal da inspiração.

Os escalenos atuam para expandir a caixa torácica superior, e os para-esternais agem no esterno e diafragma, atuando no tórax inferior e abdômen.

d) Músculos acessórios da inspiração - peitoral maior, peitoral menor, trapézio, serrátil anterior e o esternocleidomastóideo.

\subsubsection{Músculos Expiratórios}

a) Músculos abdominais - são compostos pelo reto abdominal, oblíquo interno, oblíquo externo e transverso.

$\mathrm{O}$ reto abdominal origina-se na quinta, sexta e sétima cartilagens costais e esterno e se insere no púbis.

O oblíquo externo origina-se nas últimas costelas e insere-se na crista ilíaca, tubérculo púbico e linha Alba.

O oblíquo interno origina-se na parte lateral do ligamento inguinal e fáscia tóracolombar e se insere no púbis, linha alba e cartilagem das três últimas costela.

O transverso abdominal originase na face interna das seis últimas costelas, onde se interdigitaliza com as fibras costais do diafragma, fáscia lombar, crista ilíaca e ligamento inguinal, inserindo-se na aponeurose ventral.

A função desses 4 músculos são: quando se contraem, empurram a parede abdominal para dentro, aumentando a pressão abdominal, o diafragma se desloca para cima, aumentando a pressão pleural e a saída de ar, sendo importantes músculos para a tosse e expiração forçada.

Suas inserções no gradeado costal sugerem que ao contraírem tracionam as costelas para baixo.

A função da musculatura abdominal é expiratória,porémapresentampapelimportante na ação do diafragma na inspiração.

Os abdominais facilitam a ação do diafragma, através da contração abdominal persistente, que faz com que o diafragma se encontre mais alongado no início da inspiração, além de manter fixadas as vísceras abdominais para que o diafragma possa apoiar seu centro tendíneo nas vísceras e atuar na elevação das costelas (MOORE E DALLEY, 2001).

\section{Ventilação Mecânica}

A ventilação mecânica é uma técnica que tem como objetivo substituir ou auxiliar a função ventilatória do paciente, por meio de uma pressão positiva nas vias aéreas, quando na presença de insuficiência respiratória aguda ou distúrbio que comprometa as trocas gasosas (JÚNIOR, 1998).

\subsection{Ventilador Mecânico}

Ventilador é um equipamento utilizado para proporcionar a ventilação pulmonar artificial ao paciente. O objetivo do ventilador mecânico é promover suporte ventilatório temporário, completo ou parcial, a pacientes que não conseguem respirar por vias normais devido a fatores como doenças, anestesia, defeitos congênitos (AZEREDO, 2003).

Ventiladores também são usados para permitir descanso dos músculos respiratórios até que o paciente seja capaz de reassumir a ventilação espontânea.

\section{Desmame}

A retirada do ventilador (desmame), é definida por Gonçalves (1991) como a interrupção da ventilação mecânica muitas vezes de forma gradual, em pacientes com 


\section{4 \\ insuficiência respiratória. \\ 5.1 Parâmetros parâmetros são: \\ Segundo Luce (1995), os principais \\ Melhora da insuficiência respiratória; Necessidade de $\mathrm{FiO} 2$ de $50 \%$ ou menos; Mecânica ventilatória espontânea adequada; CV pelo menos $10 \mathrm{ml} / \mathrm{kg}$; PiMáx pelo menos $-20 \mathrm{~cm} \mathrm{H} 2 \mathrm{O}$; VVM pelo menos duas vezes a necessidade de VE de repouso; Escolher o momento certo do dia para o desmame; eliminar ou minimizar a sedação; aspirar as vias aéreas e posicionar o paciente apropriadamente; mudar para ventilação espontânea na mesma $\mathrm{FiO} 2$ com ou sem CPAP; monitorizar o paciente e observar tranqüilização e gasometrias de 20 $-30 \mathrm{~min}$.}

\section{Materiais e Métodos Fisioterápicos Uti- lizados}

As técnicas utilizadas para o fortalecimento da musculatura respiratória do paciente em ventilação mecânica invasiva são: aparelho Threshold, aparelho P-Flex, alteração da sensibilidade do Ventilador Mecânico e a Estimulação Elétrica do Diafragma.

\subsection{Threshold}

O threshold é um aparelho que produz uma resistência ao inspirar (threshold inspiratório) ou quando expirar (threshold expiratório), por meio de um sistema de mola com uma válvula unidirecional e utilização de clipe nasal. Quanto mais estiver comprimida estiver a mola, maior será a resistência, que tem como unidade de medida $\mathrm{cmH} 2 \mathrm{O}$ (PRESTO 2003).

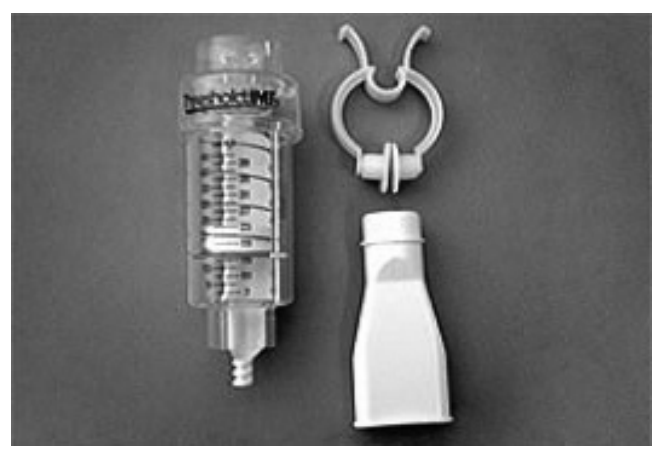

Fig. 1 - Threshold Inspiratório Fonte: Globalmed (2005)

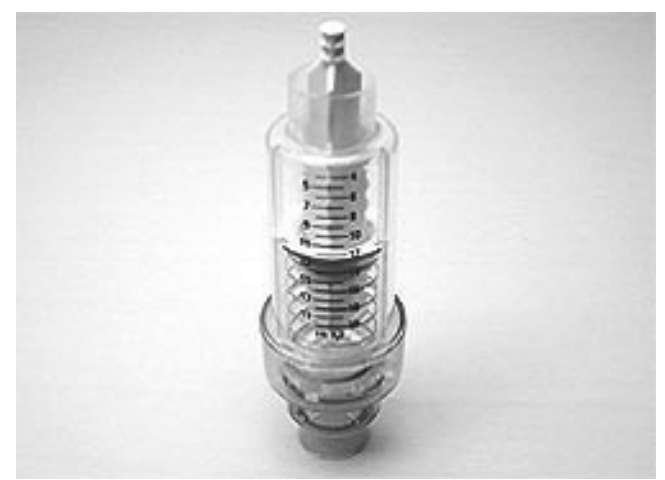

Fig. 2 - Threshold Expiratório Fonte: Globalmed (2005)

\subsection{P-Flex}

P-Flex é um sistema desenvolvido para treinamento da musculatura inspiratória, indicado para aqueles pacientes que requeiram trabalho para aumentar a força ou endurance dos músculos inspiratórios.

É composto por um conjunto de 6 orifícios que são selecionados pelo terapeuta, baseado nas condições clínicas do paciente e pela manovacuômetria para oferecer uma determinada resistência durante a inspiração. Como o resistor é um orifício, esta resistência vai ser fluxo dependente, ou seja, quanto maior o fluxo, maior a resistência e quanto menor o orifício, maior a resistência. Por isso é recomendada a utilização de um manômetro ou manovacuômetro para a monitoração da pressão, pelo menos até o paciente controlar seu fluxo inspiratório para manter determinada pressão (ANDREGHETTO, 2002).

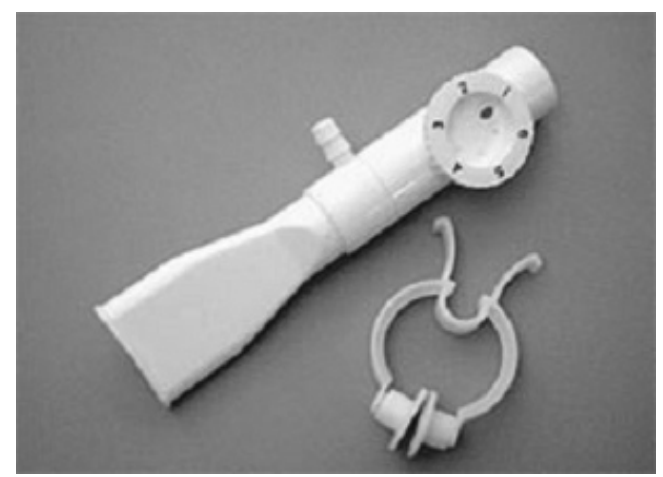

Fig. 3 - Aparelho P-Flex Fonte: Globalmed (2005)

\subsection{Alteração da Sensibilidade do Ventilador Mecânico}

Esse treinamento tem como objetivo oferecer sobrecarga inspiratória ao esforço do paciente, submetendo-o ao trabalho muscular progressivo. Quanto mais negativa é ajustada a sensibilidade do respirador mecânico, maior 
será o esforço inspiratório do paciente.

O treinamento muscular de pacientes em ventilação mecânica vem sendo realizado, porém com pouca evidência científica até o momento.

Vale ressaltar que este método não é mais utilizado, devido à imprecisão dos valores de trabalho imposto.

\subsection{Estimulação Elétrica do Diafragma (EDET)}

A contração muscular através dessa técnica é obtida com a despolarização do nervo motor, criando assim uma resposta simultânea em todas as unidades motoras existentes no músculo.

O objetivo da técnica é tentar resgatar o máximo de fibras musculares íntegras. Secundariamente, espera-se incrementar o treinamento muscular, ou seja, associar a técnica de eletroestimulação às convencionais (alteração da sensibilidade no ventilador e treinamento linear pressórico).

A estimulação é obtida pela colocação de dois eletrodos, um para cada hemitórax, sobre o ponto motor do músculo diafragma, o qual podemos localizar na altura do oitavo espaço intercostal. Para facilitar a localização, achamos o ponto traçando uma linha de $10 \mathrm{~cm}$ do mamilo para o bordo lateral do tórax e, por este ponto, traçamos outra linha para baixo, também de $10 \mathrm{~cm}$ aproximadamente. Neste ponto, podemos verificar uma contração eficaz do diafragma. Contra indicado para pacientes com lesão dérmica e que fazem uso de marcapasso cardíaco (KNOBEL, 2004).

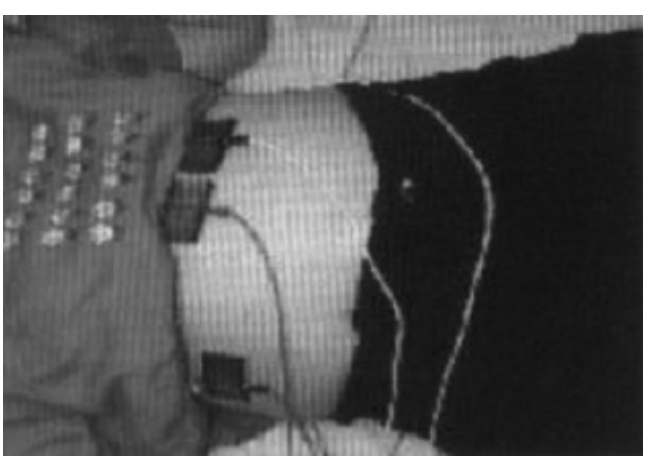

Fig.4 - Aplicação EDET

Fonte: KNOBEL (2004, pág. 142)

\section{Intervenção Fisioterapêutica}

A intervenção fisioterapêutica será realizada a partir de uma avaliação criteriosa da força da musculatura respiratória, preconizando o tratamento mais eficaz.

\subsection{Avaliação}

De acordo com Costa (1999) o fisioterapeuta para definir a resistência a ser aplicada nos aparelhos Threshold e PFlex, deve realizar em primeiro lugar, uma manovacuometria, em que se inicia com $30-50 \%$ do valor da pressão encontrada, de resistência nos aparelhos de fortalecimento muscular.

\subsection{Tratamento}

A aplicação da manovacuometria (avaliação das forças musculares) deve ser feita com o paciente de preferência sentado, numa posição confortável e com o tórax ereto. $\mathrm{O}$ procedimento consta de duas etapas. $\mathrm{Na}$ primeira, se afere a pressão "negativa" da musculatura inspiratória, pressão inspiratória máxima (Pi máx). Para verificá-la, pedese ao paciente para expirar completamente e, em seqüência, manter uma inspiração profunda; o terapeuta não deve esquecer de fechar o orifício do manovacuômetro quando o paciente estiver realizando a inspiração. Mensuramos a Pi máx ocluíndo o orifício por 20 segundos, observando e registrando a deflexão máxima do manômetro. $\mathrm{Na}$ Segunda parte, vamos aferir a pressão positiva gerada pela musculatura expiratória, pressão expiratória máxima (Pe máx). Para verificála, solicitamos que o paciente realize uma inspiração profunda e, em seguida, mantenha uma expiração com mais força e por mais tempo que puder, o orifício deve ser fechado durante a expiração. A realização da Pemáx é realizada por no mínimo três vezes, quando o melhor valor encontrado é o considerado. Deve-se eleger o melhor resultado de cada etapa. Por meio da Pimáx poderemos avaliar a capacidade de pressão inspiratória do paciente e, desta forma, avaliar a atuação do diafragma e da musculatura acessória da ventilação. Por meio da Pe max avaliamos a tosse do paciente ( CARVALHO, 2004).

Para pacientes não cooperativos realizar as oclusões durante os ciclos respiratórios desejados.

No treinamento com o aparelho Threshold, utilizar duas a três vezes ao dia 
com séries de 10 repetições com esforço de $30 \%$ a $50 \%$ da Pi max .

No treinamento com o aparelho PFlex, utilizar duas a três vezes ao dia com séries de 10 repetições, selecionando um dos 6 orifícios que oferece uma determinada resistência durante a inspiração, baseado nas condições clínicas do paciente e pela manovacuômetria.

No treinamento utilizando o ventilador mecânico, utiliza-se a carga de $50 \%$ da Pimáx, em modalidade de pressão de suporte com níveis de 5 a $7 \mathrm{cmH} 2 \mathrm{O}$ e PEEP zero. Realizar o processo por tempo de um minuto, alternando intervalos de repouso de 2 a 3 minutos.

No treinamento com Estimulação Elétrica do Diafragma (EDET), a duração mínima de aplicação deve ser de 20 a 30 min e a freqüência em torno de $30 \mathrm{~Hz}$ (podendo variar até $50 \mathrm{~Hz}$ ). Acima deste tempo, o risco de fadiga muscular é grande.

\section{Considerações Finais}

A ventilação mecânica prolongada pode resultar em atrofia e enfraquecimento dos músculos respiratórios, resultando em enfraquecimento destes músculos por desuso e, consequentemente, retardo do processo de desmame, além da possibilidade de originar outras complicações.

Em termos objetivos, o fortalecimento da musculatura respiratório visa restabelecer a função dos músculos respiratórios, melhorando sua força e endurance. Por tanto, deve ser o mais precoce possível, e o ideal é que o paciente já esteja com uma melhora da força antes de se iniciar o desmame da ventilação mecânica invasiva.

Sendo assim, a fisioterapia, buscando o fortalecimento da musculatura respiratória, é de suma importância no processo de desmame, principalmente naqueles considerados difíceis, traçando todo um plano de reabilitação.

\section{Referências}

ANDREGHETTO C. J.; FORTI G. M. P. O treinamento muscular como alternativa para desmame difícil. 3 vol. Rio de Janeiro: Revista Fisioterapia Brasil 2002.

AZEREDO,CAC. Fisioterapia Respiratória Moderna, 4ª ed Editora Manole, 2004.

CARVALHO, C. R. R. Ventilação mecânica, 8 vol. São Paulo: Editora Astrazeneca, 2004.

COSTAD,etal. Efeitos do Treinamento muscular Respiratório Durante o Processo de Desmame da Ventilação Mecânica. Rev. Brás. Terap. Intens. 1999.

COSTA, D. Fisioterapia respiratória básica, 1 vol. São Paulo: Atheneu, 1999.

DAVID CMN. Ventilação Mecânica: Da Fisiologia a Prática Clinica, [s. 1.]: Revinte, 2001.

JARDIM JRB, FELTRIM MIZ. Fisiologia Muscular Respiratória, [s. 1.]: Atheneu, 1998.

JUNIOR, CA, DO AMARAL G. Assistência Ventilatória Mecânica, [s. 1.]: Atheneu, 1998.

KNOBEL, ELIAS, Terapia intensiva: Pneumologia e Fisioterapia Repiratória, São Paulo: Atheneu, 2004.

KEITH L. MOORE E ARTHUR F. DALLEY Anatomia Orientada para Clínica Médica $4^{\mathrm{a}} \mathrm{ed}$. Rio de Janeiro: Guanabara Koogan, 2001.

LUCE, JOHN M. Tratamento Respiratório Intensivo. $2^{\text {a }}$ edição, Rio de Janeiro: Revinter, 1995.

PRESTO, B, Fisioterapia Respiratória: Uma Nova Visão. Rio de Janeiro: Bruno Presto, 2003.

WEST, JOHN B. Fisiologia Respiratória Moderna. 3a edição, São Paulo: Manole,1990.

www.globalmed.com.br, autor: Powered by Idéia Click. Acesso: 19/03/2005, 17:00 Hs.

\section{Informação bibliográficas:}

Conforme a NBR 6023:2002 da Associação Brasileira de Normas Técnicas (ABNT), este texto científico publicado em periódico eletrônico deve ser citado da seguinte forma:

CUNHA, C. S.; SANTANA, E. R. M.; FORTES, R. A.. Técnicas de Fortalecimento da Musculatura Respiratória Auxiliando o Desmame do Paciente em Ventilação Mecânica Invasiva. Cadernos UniFOA, Volta Redonda, ano III, n. 6, abril. 2008. Disponível em: $<$ http://www.unifoa.edu.br/pesquisa/ caderno/edicao/06/80.pdf> 